\title{
Production of Granulomatous Inflammation in Lungs of Rat Pups and Adults by Sephadex Beads
}

\author{
MIO MIYAKE, MASASHI MORISHITA, KOMEI ITO, AKEMI ITO, SHINPEI TORII, AND \\ TATSUO SAKAMOTO
}

Department of Pediatrics [M.Mi., A.I., S.T., T.S.], Nagoya University Graduate School of Medicine, Nagoya 466-8550, Japan; and Aichi Children's Health and Medical Center [M.Mo., K.I.], Obu 474-0031, Japan

\begin{abstract}
Granulomatous inflammation is a process that involves mononuclear leukocytes as well as other inflammatory cells. The heterogeneity of its appearance may be due to the variety of cytokines and chemokines that are involved. In this study, we compared granuloma formation and bronchoalveolar leukocyte differential in the lungs of rats (2- and 8-wk-old) that were treated intravenously with Sephadex beads. In addition, the kinetics of cytokine and chemokine production was determined in these groups. In adults, the beads caused lung granulomas associated with infiltration of eosinophils and neutrophils and increased eosinophil and neutrophil counts in the bronchoalveolar lavage fluid within $16 \mathrm{~h}$. In pups, the granulomas were formed slowly and did not reach the size achieved in adults. Eosinophils and neutrophils were sparsely found in the periphery of the granulomas, even at $32 \mathrm{~h}$. Pups were also unable to respond rapidly to Sephadex bead treatment with eosinophil and neutrophil infiltration in the bronchoalveolar lavage fluid. Tumor necrosis factor- $\alpha$ was significantly increased in both groups, but the cytokine was
\end{abstract}

\section{ABSTRACT}

lower in pups than in adults. Interferon- $\gamma$ and eotaxin were increased only in adults, and IL- 4 and regulated on activation, normal $\mathrm{T}$ cell expressed, and secreted was increased only in pups. In conclusion, the i.v. administration of Sephadex beads produced granulomatous inflammation in the lungs of adult rats, but pups were unable to respond as rapidly to the treatment. In addition, the difference in response between the two age groups was associated with the kinetics of cytokine and chemokine production. (Pediatr Res 56: 205-211, 2004)

$\quad$ Abbreviations
BALF, bronchoalveolar lavage fluid
IFN- $\boldsymbol{\gamma}$, interferon- $\gamma$
PAS, periodic acid-Schiff
RANTES, regulated on activation, normal T cell expressed,
and secreted
Th2, T helper cell type 2
TNF- $\alpha$, tumor necrosis factor- $\alpha$

Granulomatous inflammation is a fundamental finding of many bacterial, fungal, and parasitic human diseases, and mononuclear leukocyte infiltration is a common histopathologic feature. In addition, many other inflammatory cells are recruited to the lesion or activated in situ, resulting in granuloma development with significant heterogeneity in histologic appearance (1-3). Difference in the cellular composition of granulomas may depend on the pattern of cytokine and chemokine involvement (3). Warren (4) offered a classification of granulomas on the basis of the degree of antigen-specific immune involvement and cellular turnover. On the basis of this classification, granulomas associated with infectious agents such as Mycobacteria species, fungi, and helminths were con-

Received January 20, 2003; accepted March 2, 2004.

Correspondence: Tatsuo Sakamoto, M.D., Department of Pediatrics, Nagoya University Graduate School of Medicine, 65 Tsurumai-cho, Showa-ku, Nagoya 466-8550, Japan; e-mail: tatsuos@med.nagoya-u.ac.jp

This study was granted by the Ministry of Health, Labour and Welfare of Japan.

DOI: 10.1203/01.PDR.0000132663.28603.5B sidered hypersensitivity-type and inert poorly digestible particles induced nonimmune foreign body-type lesions.

Two experimental murine models that correspond to the two-typed granulomatous inflammation in human are available (3-6). One is a hypersensitivity-type granuloma induced by the embolism of isolated Schistosoma mansoni eggs or particles coated with its antigens. The second is a foreign body-type granuloma induced via the embolism of uniformly sized polysaccharide (Sephadex) beads. Sephadex beads elicited lung inflammatory responses to a lesser degree than Schistosoma mansoni eggs and antigens, and the granulomas were composed of different cell populations $(3,6)$. In these experimental models, macrophage-derived IL- 1 and tumor necrosis factor- $\alpha$ (TNF- $\alpha$ ) played fundamental roles in the induction and sustenance of the granulomas $(3,5,6)$. In addition, other cytokines and chemokines were probably involved, but the details were not clearly identified $(3,6)$.

In rat and guinea pig models, Sephadex beads administered intravenously or intratracheally can cause granulomatous lesions with considerable accumulations of eosinophils and neu- 
trophils in the lungs $(7-10)$. When these particles initiated emboli in the pulmonary microvasculature, mononuclear cells, eosinophils, and neutrophils accumulated in the area and a granuloma was formed around the particle. The granuloma gradually expanded, and inflammatory cells infiltrated the adjoining pulmonary alveoli, respiratory tract, and blood vessels $(7,8,10)$. In contrast, only a limited mononuclear infiltrate was found in the Sephadex-treated lungs of a mouse model $(3,6)$. An increased number of eosinophils in the bronchoalveolar lavage fluid (BALF) was considered to reflect the eosinophilic accumulation in the lesion (9,11-13). IL-5-mediated (14), eotaxin-mediated (15), vascular cell adhesion molecule-1mediated $(13,14)$, and intracellular adhesion molecule-1 (ICAM-1)-mediated $(13,14)$ pathways contributed to the eosinophilic infiltration into the BALF of Sephadex-treated animals. Therefore, a fundamental common mechanism exists between eosinophilic infiltration into the lungs of Sephadextreated and allergen-exposed animals. Animal models using Sephadex beads have been used to identify pathways involved in eosinophil recruitment.

Mononuclear leukocytes play a crucial role in development and maintenance of lung granulomas. We are interested in differences between infant and adult mononuclear leukocytes in terms of their responses to foreign products causing granuloma formation. However, differences between humans and animals of varying ages have not been studied. Recent studies (16-19) suggested that neutrophil-mediated inflammation, rather than eosinophil-mediated inflammation, contributed to symptoms of asthma in infants and children. Just et al. (18) reported that the number of eosinophils in the BALF was lower in infants with asthma than in children with asthma and was related to allergic sensitization but not to severity of asthma. Thus, there may be differences between infants and adults in the role of eosinophils and neutrophils in the pathogenesis of asthma $(20,21)$. These findings suggest that there are differences between infant and adult lungs in the participation of eosinophils and neutrophils in granulomatous changes.

In the present study, we compared lung granuloma formation and bronchoalveolar leukocyte differential in two age groups of rats ( 2 and 8 wk old) that were treated with Sephadex beads. In addition, the levels of inflammatory cytokines (TNF- $\alpha$ and IL-4), interferon- $\gamma$ (IFN- $\gamma$ ), and chemokines [eotaxin and regulated on activation, normal $\mathrm{T}$ cell expressed, and secreted (RANTES)] in the BALF were measured to determine whether different responses to Sephadex beads were due to the kinetics of cytokine and chemokine production.

\section{METHODS}

Animals. All animal experimentation was conducted with previous approval of the Animal Ethics Committee of the Institute for Laboratory Animal Research, Nagoya University Graduate School of Medicine, which operates under the Guidelines for the Care and Use of Laboratory Animals of the Institute for Laboratory Animal Research (1989, Nagoya, Japan). Pathogen-free male Wistar rats at $2 \mathrm{wk}(36-41 \mathrm{~g})$ and 8 wk (280-300 g) of age were purchased (Japan SLC Inc., Hamamatsu, Japan) $2 \mathrm{~d}$ before experiment. All rats were housed in a temperature-controlled room and given free access to food and water. Pups that had not been weaned were housed with dams in polycarbonate cages with polyester filter covers.

Materials. Sephadex beads (G-50 superfine; Pharmacia \& Upjohn Diagnostics AB, Uppsala, Sweden) were prepared as previously described (22). Briefly, the beads were autoclaved for $30 \mathrm{~min}$ and suspended in pathogen-free $0.9 \%$ sodium chloride $(0.9 \%$ saline $)$ for at least $48 \mathrm{~h}$ at $4^{\circ} \mathrm{C}$. Hanks' balanced salt solution and $37 \%$ formalin were purchased from Sigma Chemical Co. Ltd. (St. Louis, MO, U.S.A.), pentobarbital sodium was purchased from Abbott Laboratories (North Chicago, IL, U.S.A.), reagents for Turk's and periodic acid-Schiff (PAS) stains were purchased from Katayama Chemical Industries (Osaka, Japan), a thiazine-eosin staining kit (Diff-Quik stain) was purchased from Kokusai Shiyaku Co. Ltd. (Kobe, Japan), reagents for hematoxylin-eosin and May-Giemsa's stains were purchased from Muto Pure Chemicals Co. Ltd. (Tokyo, Japan), and pathogen-free $0.9 \%$ saline was purchased from Otsuka Chemical Co. (Tokyo, Japan).

Protocol. Groups of at least four rat adults and pups were anesthetized with pentobarbital (40 mg/kg intraperitoneally) and either $1 \mathrm{~mL}$ (adult) or $0.5 \mathrm{~mL}$ (pup) of $0.9 \%$ saline that contained $0,0.5 \times 10^{4}, 1.5 \times 10^{4}, 5 \times 10^{4}, 15 \times 10^{4}$, or 50 $\times 10^{4}$ particles of Sephadex beads $/ \mathrm{kg}$ was injected into the caudal vein with. The BALF and lungs were collected $16 \mathrm{~h}$ later for analysis, as described below. Doses larger than $10^{6}$ particles $/ \mathrm{kg}$ were lethal to some rats in preliminary studies.

In a time-course study, groups of at least four rats were treated with $15 \times 10^{4}$ particles $/ \mathrm{kg}$, and the BALF was obtained from adult $(0,2,6,16$, and $32 \mathrm{~h}$ after treatment) and pup $(0,16$, and $32 \mathrm{~h}$ after treatment) rats. For measuring the number of Sephadex beads plugging small vessels in the lung by light microscopy, groups of five rat adults and pups were treated with the beads $\left(5 \times 10^{4}, 15 \times 10^{4}\right.$, or $50 \times 10^{4}$ particles $/ \mathrm{kg}$ intravenously), and their lungs were collected $1 \mathrm{~h}$ later.

Bronchoalveolar lavage and cell counting. Rats were given an overdose of pentobarbital $(120 \mathrm{mg} / \mathrm{kg}$ intraperitoneally). Their lungs were lavaged 10 times with $1-\mathrm{mL}$ (pup) or $2-\mathrm{mL}$ (adult) aliquots of $0.9 \%$ saline via a tracheal cannula, $8 \mathrm{~mm}$ long with a $1.0 \mathrm{~mm}$ (pup) or $1.3 \mathrm{~mm}$ (adult) inner diameter, introduced through a tracheostomy. Lavage fluids were centrifuged at $800 \times g$ for $10 \mathrm{~min}$ at $4^{\circ} \mathrm{C}$, and cell pellets were resuspended in $1 \mathrm{~mL}$ of Hanks' balanced salt solution. After centrifugation at $15,000 \times g$, supernatants were stored at $-40^{\circ} \mathrm{C}$ before measurement of TNF- $\alpha$, IL-4, IFN- $\gamma$, eotaxin, and RANTES. Cells were counted under a light microscope in a Burker-Turk chamber (Erma Optical Works, Tokyo, Japan) after adding $100 \mu \mathrm{L}$ of the cell suspension to $100 \mu \mathrm{L}$ of Turk's reagent. Differential cell counts were made using cytospin preparations (Cytospin 3; Shandon Scientific Ltd., Cheshire, U.K.) stained with a Diff-Quik stain. A total of 800 cells were counted under $\times 400$ magnification, and the percentage and absolute number of each type were calculated. Cells were identified as mononuclear cells, neutrophils, eosinophils, and shed epithelial cells by standard morphologic techniques.

Histologic analysis. After lavage, lungs were removed and inflated with $10 \%$ phosphate-buffered formalin to a pressure of $25 \mathrm{cmH}_{2} \mathrm{O}$. Paraffin-embedded sections (4 $\mu \mathrm{m}$ thick) of the 
tracheobronchi and lungs were stained with hematoxylin-eosin, PAS, or May-Giemsa's stain and evaluated by light microscopy.

Areas of at least 10 granulomas with visible central Sephadex beads from different May-Giemsa's-stained sections of each lung were measured. A photographic image of each granuloma (magnification $\times 200$ ) was clipped from a photographic printing paper (Fuji Photo Film Co., Tokyo, Japan) and weighed. The weight of a photographic image of a square 100 $\mu \mathrm{m}$ on a side (magnification $\times 200$ ), determined by an objective micrometer, was measured using the same method. We calculated a granuloma area on the basis of the ratio of both weight.

Sephadex beads in an area of lung cross-section stained with PAS stain were counted. At least 10 fields from different sections of each lung were measured under $\times 40$ magnification.

Cytokine/chemokine assay. Concentrations of cytokines and chemokines were measured using commercially available kits for TNF- $\alpha$ and RANTES (BioSouce International, Camarillo, CA, U.S.A.), IL-4 and IFN- $\gamma$ (BD Pharmingen, San Diego, CA, U.S.A.), and eotaxin (R\&D systems Inc., Minneapolis, MN, U.S.A.). Detection limits for TNF- $\alpha$, IL-4, IFN- $\gamma$, eotaxin, and RANTES were $4,0.5,5,3$, and $20 \mathrm{pg} / \mathrm{mL}$, respectively. IL-5 protein level in the BALF was not measured because there was no commercially available specific ELISA kit.

Statistical analysis. All values were expressed as the mean \pm SEM. An unpaired $t$ test (two-tailed) was used to evaluate the significance of the difference between two independent groups with equal variance, which was assessed with the $F$ test. Otherwise, the Mann-Whitney $U$ test (two-tailed) was used. $P$ $<0.05$ was considered to be statistically significant.

\section{RESULTS}

Leukocyte counts in the BALF. No treatment-related effects on body weight were observed (data not shown). Approximately $95 \%$ of the BALF was recovered with minimal contamination by red blood cells. The total cell count in the BALF was $\sim 1.5$ times greater in control adults than control pups, and this difference was greater after Sephadex bead treatment. Dose-dependently increased numbers of eosinophils and neutrophils but not mononuclear cells were seen in the BALF from the adults $16 \mathrm{~h}$ after treatment (Fig. 1). The dose-dependent responses of eosinophils and neutrophils were also observed in the pups; however, the alteration was significantly smaller than that in adults (Fig. 1). Shed epithelial cells were barely detectable in the BALF in either group.

Mononuclear cells, eosinophils, and neutrophils were significantly increased in the BALF from adults $6 \mathrm{~h}$ after treatment (Fig. 2). In contrast, pups showed only an increased eosinophil count at $32 \mathrm{~h}$ and neutrophil count at $16 \mathrm{~h}$ (Fig. 2).

Cytokine/chemokine levels in the BALF. In the adults, the concentrations of TNF- $\alpha$, IFN- $\gamma$, and eotaxin in the BALF increased in a dose-dependent manner after treatment (Fig. 3). Although RANTES was released from resident cells in controls, its levels were unaffected by treatment. In pups, levels of IL-4 and RANTES increased dose-dependently after treatment,

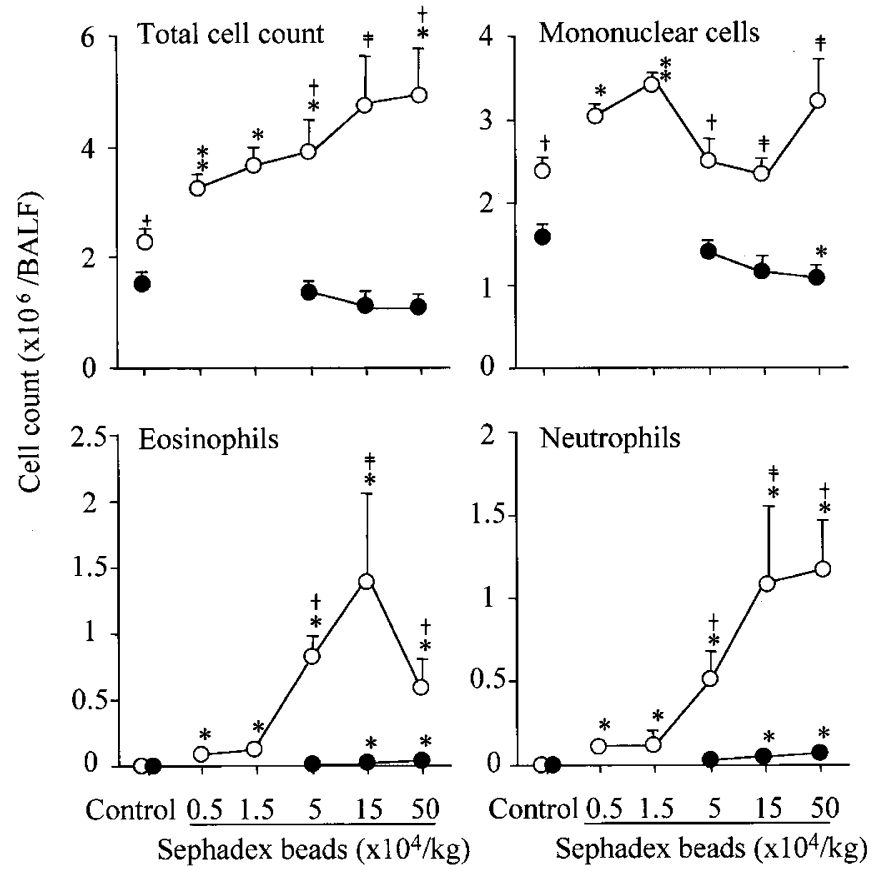

Figure 1. Effect of Sephadex beads $\left(0.5 \times 10^{4}, 1.5 \times 10^{4}, 5 \times 10^{4}, 15 \times 10^{4}\right.$, or $50 \times 10^{4}$ particles $/ \mathrm{kg}$ ) on leukocyte counts in the BALF $16 \mathrm{~h}$ after their injection in two groups of rats at $2 \mathrm{wk}(\bullet)$ and $8 \mathrm{wk}(\bigcirc)$ of age. The beads were suspended in $0.9 \%$ saline and administered via the caudal vein. Control animals were given only $0.9 \%$ saline intravenously. Results are expressed as means $\pm \operatorname{SEM}(n=4-7) .{ }^{*} P<0.05$ and ${ }^{*} P<0.01 v s$ the control group; ${ }^{+} P$ $<0.05$ and ${ }^{++} P<0.01$ compared between the two groups of rats at 2 and 8 wk of age, assessed with the unpaired $t$ test or Mann-Whitney $U$ test.

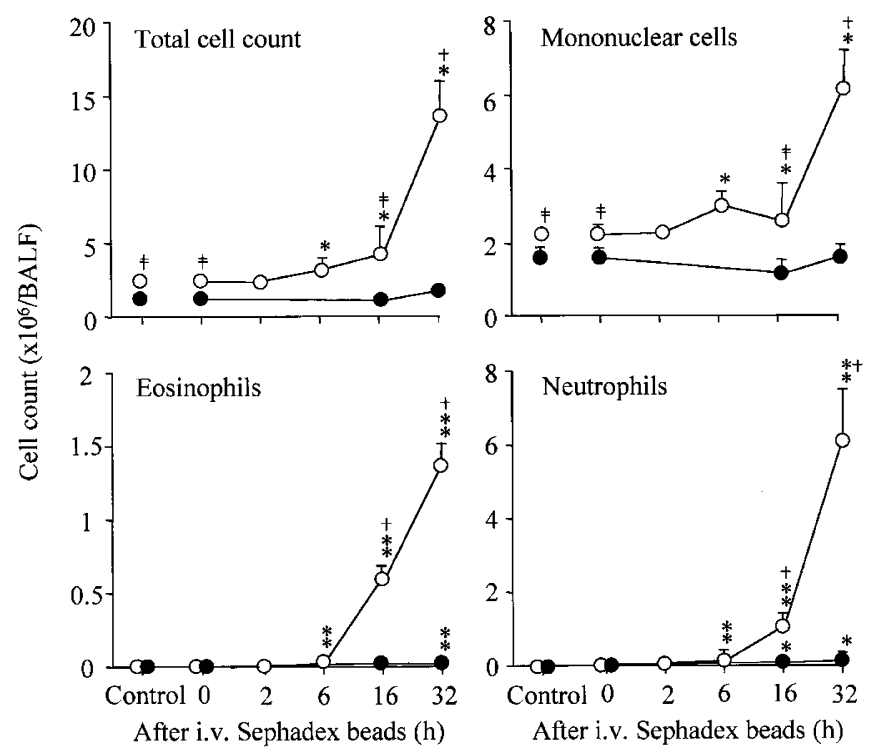

Figure 2. Time course of changes in leukocyte cell counts after Sephadex bead injection in two groups of rats at $2 \mathrm{wk}(-)$ and $8 \mathrm{wk}(\bigcirc)$ of age. The BALF was collected at $0,2,6,16$, or $32 \mathrm{~h}$ after treatment with the beads $(15$ $\times 10^{4}$ particles $/ \mathrm{kg}$ intravenously). Controls were given $0.9 \%$ saline intravenously, and BALF was collected $16 \mathrm{~h}$ later. Results are expressed as means \pm $\operatorname{SEM}(n=4-7) .{ }^{*} P<0.05$ and ${ }^{* *} P<0.01$ vs the control group; ${ }^{+} P<0.05$ and ${ }^{++} P<0.01$ compared between the two groups of rats at 2 and 8 wk of age, assessed with the unpaired $t$ test or Mann-Whitney $U$ test.

whereas the levels of IFN- $\gamma$ and eotaxin were not affected (Fig. 3). Although TNF- $\alpha$ was significantly released into the BALF in pups, the response was significantly lower than in adults. 


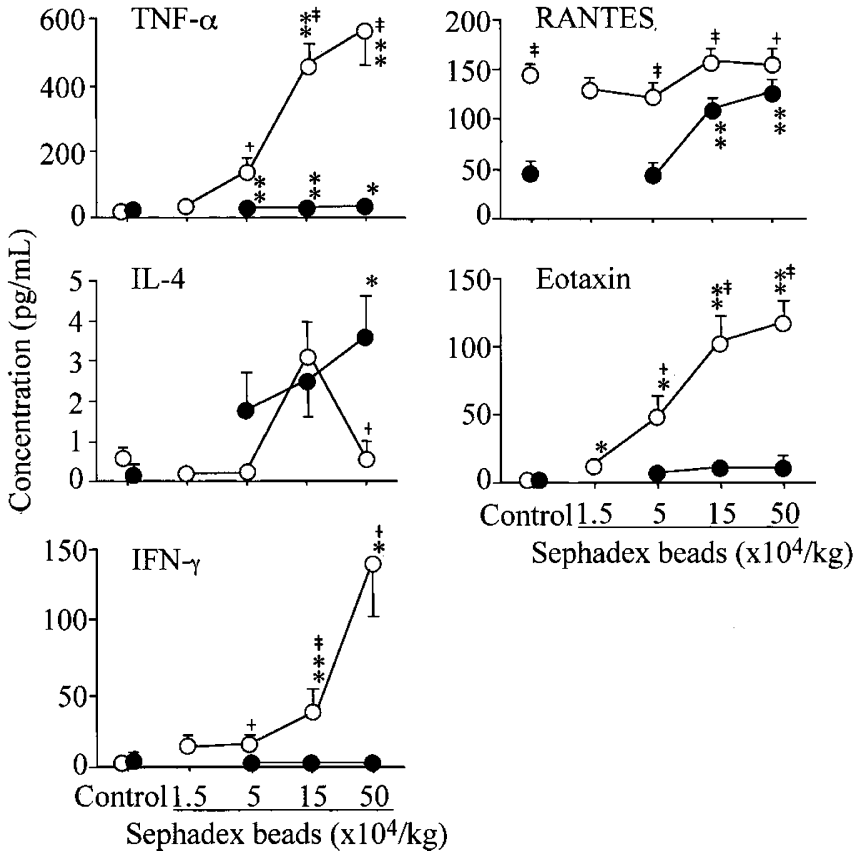

Figure 3. Effects of an i.v. injection of Sephadex beads $\left(0.5 \times 10^{4}, 1.5 \times 10^{4}\right.$, $5 \times 10^{4}, 15 \times 10^{4}$, or $50 \times 10^{4}$ particles $/ \mathrm{kg}$ ) on the concentrations of TNF- $\alpha$, IL-4, IFN- $\gamma$, eotaxin, and RANTES in the BALF obtained from two groups of rats at $2 \mathrm{wk}(\bigcirc)$ and $8 \mathrm{wk}(\bigcirc)$ of age. BALF was collected $16 \mathrm{~h}$ after treatment with the beads. Controls were given $0.9 \%$ saline intravenously. Results are expressed as means $\pm \operatorname{SEM}(n=4-7) . * P<0.05$ and ${ }^{* *} P<0.01$ vs the control group; ${ }^{+} P$ $<0.05$ and ${ }^{++} P<0.01$ compared between the two groups of rats at 2 and $8 \mathrm{wk}$ of age, assessed with the unpaired $t$ test or Mann-Whitney $U$ test.

Histologic investigation of lung preparations. Pups had smaller alveolar spaces and thinner alveolar walls than adults. No inflammatory cell infiltrated into the lung before treatment (Fig. $4 a$ and $d$ ), and a variety of inflammatory responses were observed in lungs after treatment with Sephadex beads. In the adults, large granulomas were found $16 \mathrm{~h}$ after treatment; the lesions were composed predominantly of mononuclear cells with fewer eosinophils and neutrophils, and eosinophils and neutrophils were noticeable in the periphery of the lesions (Fig. $4 b$ and $c$ ). Small arteries clogged with beads showed granulomatous arteritis. Mononuclear cells, eosinophils, and neutrophils increased the number of cells in the interstitium. However, few inflammatory changes were observed in the airway lumen and wall that were not adjacent to the granulomatous lesions (data not shown). In the pups, beads were surrounded by a thin corona of mononuclear cells, neutrophils were barely present in the outer rim of the infiltrates, and eosinophils were detected in the lesion (Fig. $4 e$ and $f$ ).

In the time-course study, granulomatous changes with eosinophilic and neutrophilic infiltration were first observed in adults at $6 \mathrm{~h}$, and the granuloma greatly developed in size by $16 \mathrm{~h}$ (Fig. $5 a-c$ ). After $32 \mathrm{~h}$, the granulomas became larger, reaching up to $\sim 44,000 \mu \mathrm{m}^{2}$ (Fig. $5 d$ ). In pups, mononuclear cell infiltrate was slightly observed around the beads at $16 \mathrm{~h}$ (Fig. 5e). At $32 \mathrm{~h}$, markedly dense mononuclear cell infiltrate appeared around the beads, and both eosinophils and neutrophils were barely detected in the periphery of the granuloma (Fig. 5f). The area of the granuloma was significantly smaller
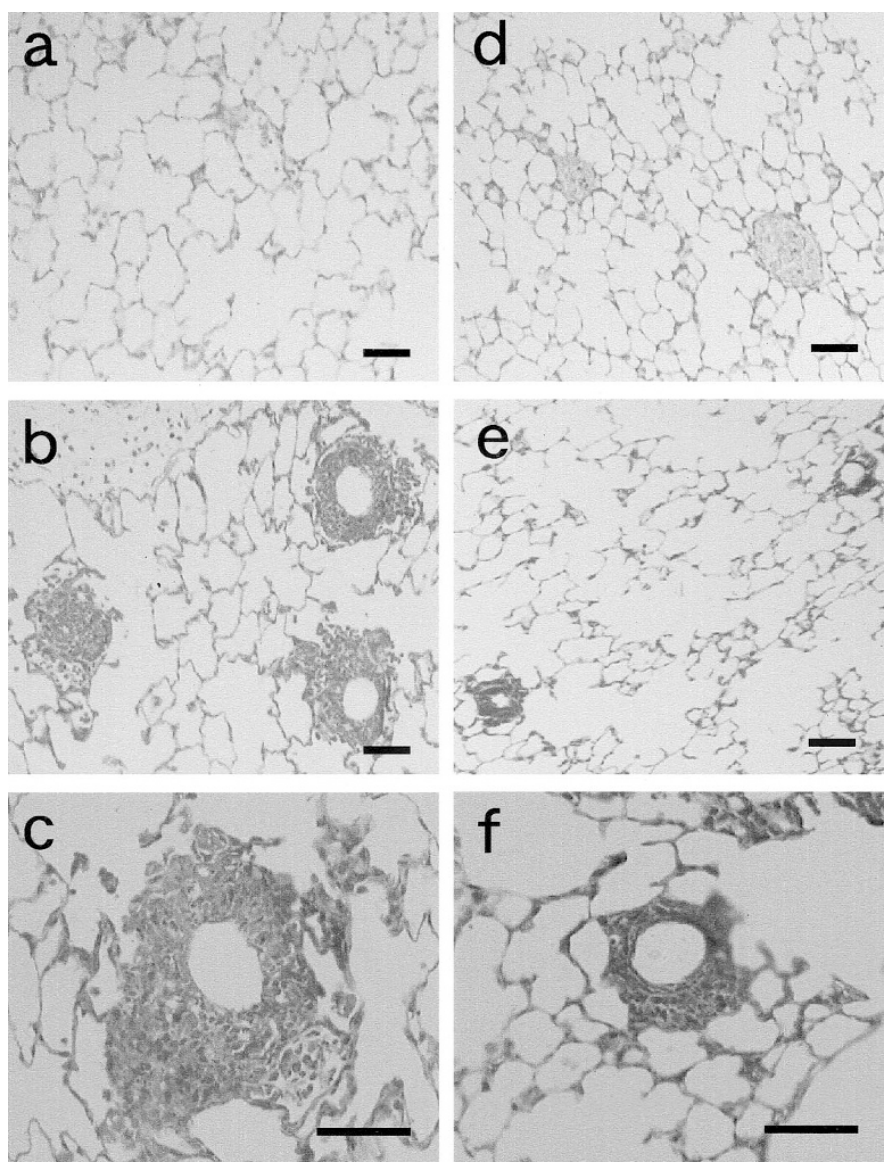

Figure 4. Histopathologic features of pulmonary inflammation induced by an i.v. injection of Sephadex beads $\left(15 \times 10^{4}\right.$ particles $\left./ \mathrm{kg}\right)$ in two groups of rats at 2 and $8 \mathrm{wk}$ of age. The lungs were removed $16 \mathrm{~h}$ after treatment with the beads, and paraffin-embedded sections ( $4 \mu \mathrm{m}$ thick) were stained with MayGiemsa's stain. Lung histology was assessed by light microscopy. (a) Lung section from control rats 8 wk old. ( $b$ and $c$ ) Lung sections from Sephadex bead-treated rats at $8 \mathrm{wk}$ of age. $(d)$ Lung section from control rats at $2 \mathrm{wk}$ of age. ( $e$ and $f$ ) Lung sections from Sephadex bead-treated rats at 2 wk of age. Bars $=50 \mu \mathrm{m}$.

in pups than in adults at $16 \mathrm{~h}(3,870 \pm 586$ versus $14,329 \pm$ $1,302 \mu \mathrm{m}^{2}$, respectively) and $32 \mathrm{~h}(6,530 \pm 704$ versus 44,109 $\pm 2,288 \mu \mathrm{m}^{2}$, respectively; Fig. 6 ). In both groups, the area of each granuloma was correlated with interval after treatment (Fig. 6) but not the number of the beads administered (data not shown).

There was no significant difference between the two age groups in numbers of the beads in a cross-section area lung (Fig. 7). Nevertheless, the bronchoalveolar leukocyte profiles in response to the beads were remarkably different between the two groups.

\section{DISCUSSION}

Sephadex beads caused marked granulomatous lesions around the beads in adult rats, clogging small vessels in the lung. Mononuclear cells were the primary cells found in the lesion, but eosinophils and neutrophils also accumulated appreciably in the lesions and their surroundings. These results are consistent with previous reports $(7,10)$. Examination of the BALF also revealed significant increased counts of eosinophils 


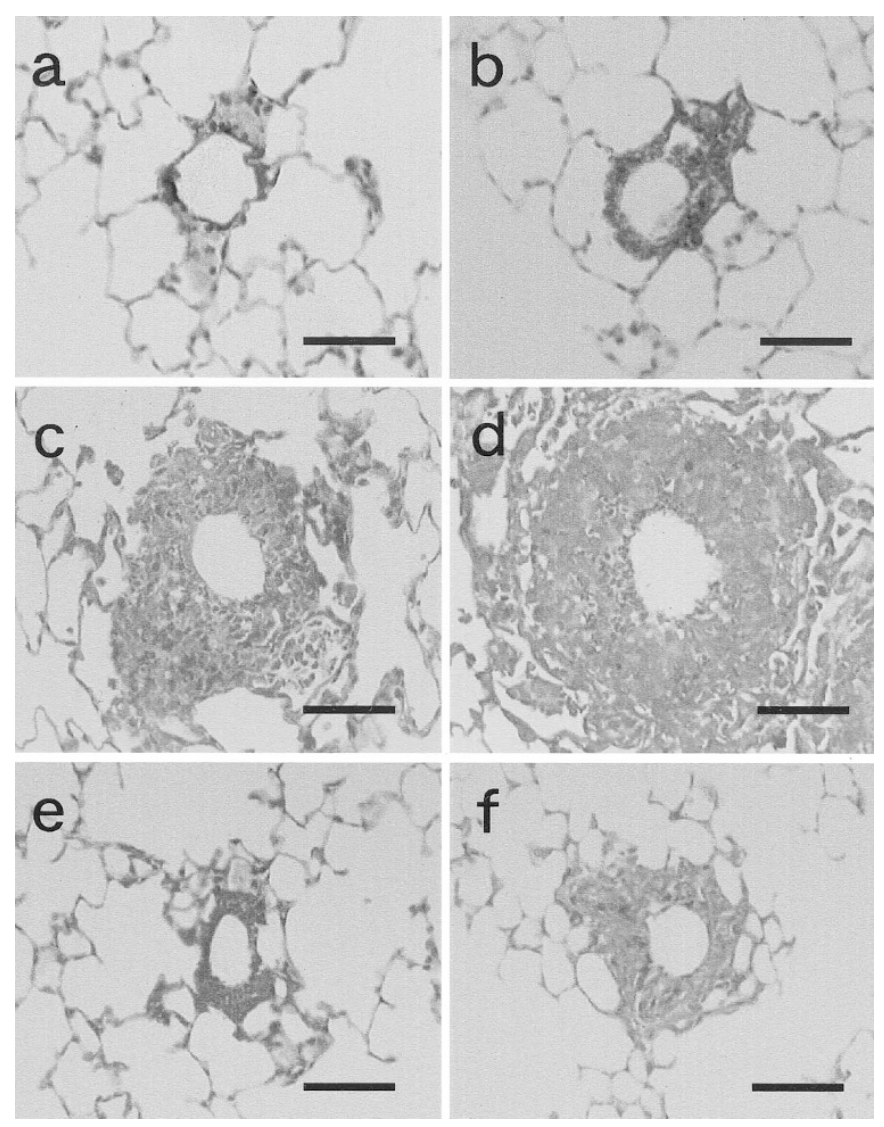

Figure 5. Time course of histopathologic features of pulmonary inflammation induced by an i.v. injection of Sephadex beads $\left(15 \times 10^{4}\right.$ particles $\left./ \mathrm{kg}\right)$ in two groups of rats at 2 and $8 \mathrm{wk}$ of age. The lung samples were collected from rats aged $8 \mathrm{wk}$ at $2 \mathrm{~h}(a), 6 \mathrm{~h}(b), 16 \mathrm{~h}(c)$, and $32 \mathrm{~h}(d)$ after treatment with the beads and from rats aged $2 \mathrm{wk}$ at $16 \mathrm{~h}(e)$ and $32 \mathrm{~h}(f)$ after treatment. Lung preparations were stained with May-Giemsa's stain and assessed by light microscopy. Bars $=50 \mu \mathrm{m}$.

and neutrophils, reflecting inflammation of lung tissue. However, the number of mononuclear cells observed in the BALF did not increased as sharply. The granulomas in pups formed slowly and did not reach the same size observed in adults. In addition, eosinophils and neutrophils were sparsely found in the periphery of the granulomas, even at $32 \mathrm{~h}$. Thus, pups were unable to respond rapidly to Sephadex bead treatment with eosinophil and neutrophil infiltration in the BALF.

ICAM-1-mediated mechanisms were involved in lung eosinophilic and neutrophilic infiltration in the Sephadex-treated model (14). In addition, ICAM-1-mediated mechanisms may play an important role in lung granuloma formation in the Sephadex-treated model, because CD11a/CD18 and CD11b/ CD18, ligands of ICAM-1 on endothelial cells, are densely distributed on mononuclear cells, primarily mediating granuloma formation $(23,24)$. Sephadex bead treatment up-regulated ICAM-1 expression in rat lungs, and dexamethasone treatment prevented increased ICAM-1 expression and abolished both lung granuloma formation and infiltration of eosinophils and neutrophils into the BALF (13). TNF- $\alpha$ increased expression of ICAM-1, which suggests that this cytokine contributes to lung responses involving ICAM-1-mediated mechanisms, such as the development and maintenance of lung granuloma

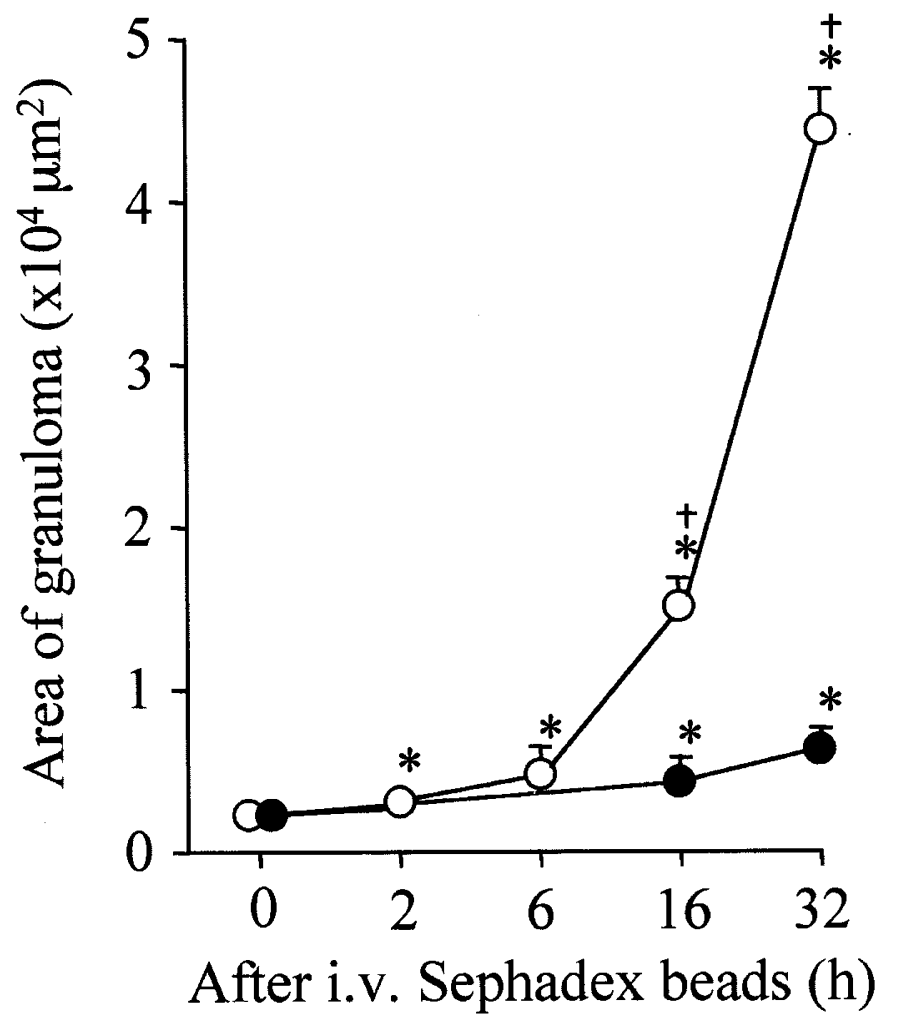

Figure 6. Area of each lung granuloma in two groups of rats at $2 \mathrm{wk}(\mathbf{)})$ and 8 wk $(\bigcirc)$ of age at various intervals after an i.v. injection of Sephadex beads $\left(15 \times 10^{4}\right.$ particles $\left./ \mathrm{kg}\right)$. Areas of at least 10 granulomas from different May-Giemsa's-stained sections of each lung were measured. Results are expressed as means $\pm \operatorname{SEM}(n=4-7) .{ }^{*} P<0.01 \mathrm{vs}$ the control group ${ }^{+} P$ $<0.01$ compared between the two groups of rats at 2 and $8 \mathrm{wk}$ of age, assessed with the unpaired $t$ test or Mann-Whitney $U$ test.

and leukocyte accumulation in the lung (23-27). Pretreatment with a TNF receptor fusion protein (Ro 45-2081) significantly inhibited infiltration of eosinophils and neutrophils into the BALF after antigen challenge in sensitized rats (28), indicating a requirement for TNF- $\alpha$ in accumulation of eosinophils and neutrophils. However, the same dose of Ro 45-2081 used in the study (28) reduced only neutrophilic infiltration into the BALF in Sephadex-treated rats (29). Thus, TNF- $\alpha$ may play a role in neutrophil recruitment into the lungs of Sephadex-treated rats, and the eosinophil response to Sephadex beads may be resistant to TNF blockade. Because Sephadex beads caused a smaller dose-dependent release of TNF- $\alpha$ into the BALF of pups than adults in the present study, this may explain differences in lung granuloma development and neutrophilic infiltration in the two age groups.

In the present study, the protein expression of IFN- $\gamma$ was up-regulated in adults but not in pups. This is not consistent with a previous study (30) that showed that gene or protein expression of IFN- $\gamma$ was not increased after Sephadex bead treatment even in the adult rat lung. Unfortunately, there is no clear explanation for this difference. IFN- $\gamma$ has proinflammatory effects, including an amplifying effect of TNF- $\alpha$ from alveolar macrophages $(31,32)$. Therefore, in our adult rat model, increased IFN- $\gamma$ may have augmented the development of lung granulomas and neutrophilic infiltration into the BALF through up-regulation of TNF- $\alpha$-mediated mechanisms. 


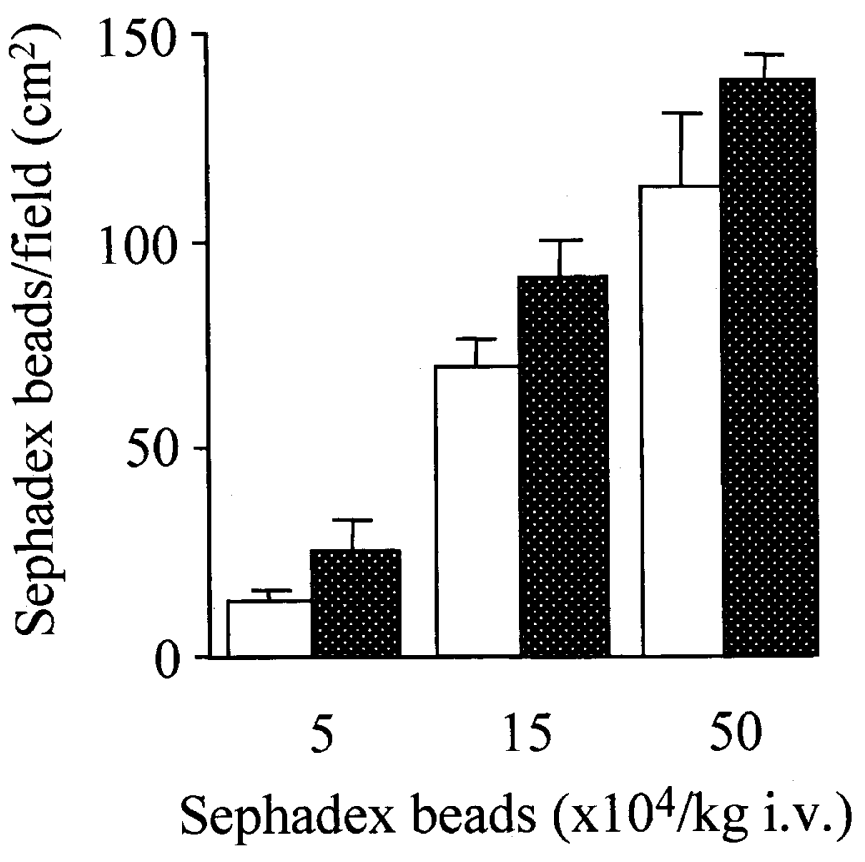

Figure 7. The number of Sephadex beads plugging small vessels in the lung in an area of lung cross-section stained with PAS stain. Lung preparations were obtained from two groups of rats at $2 \mathrm{wk}(\square)$ and $8 \mathrm{wk}(\boldsymbol{\square})$ of age, which were administered the beads $\left(5 \times 10^{4}, 15 \times 10^{4}\right.$, or $50 \times 10^{4}$ particles $\left./ \mathrm{kg}\right)$ intravenously and killed $1 \mathrm{~h}$ later. The number of Sephadex beads on at least 10 fields from different sections of each lung was measured under $\times 40$ magnification. Results are expressed as means $\pm \operatorname{SEM}(n=5)$. Statistical significance was assessed with the unpaired $t$ test or Mann-Whitney $U$ test. There was no significant difference in the number of the beads between the two groups at 2 and 8 wk of age.

There is increasing evidence that eotaxin plays an important role in eosinophil recruitment in lung tissues (33-36). Blocking antibodies to eotaxin suppressed eosinophilic infiltration in the BALF from rats that were treated with Sephadex beads (15). In addition, the time course of eotaxin expression after Sephadex bead administration was related to the appearance of eosinophilic infiltration in the rat lungs $(30,37)$. These studies show the role played by eotaxin in eosinophil recruitment in the lung tissue. After Sephadex bead injection, both eotaxin and eosinophils increased in a dose-related manner in the BALF from adults, which was consistent with previous results $(15,30,37)$. In contrast, no treatment-related changes in eotaxin were observed in our pup model. However, RANTES in the BALF was significantly increased in pups but not in adults. Previous study (30) also showed that Sephadex bead treatment had no effect on gene or protein expression of RANTES in lungs. These studies indicate that RANTES does not contribute to lung eosinophilic infiltration in the Sephadex-treated adult rat model. RANTES is a powerful eosinophil chemoattractant, being as effective as C5a and two to three times more potent than MIP- $1 \alpha(38,39)$. Therefore, RANTES may play a role in inducing eosinophilic infiltration in the lung only in pups. However, our results provide no explanation for why only rat pups produced RANTES but not eotaxin after Sephadex bead treatment.

Sephadex beads evoked lung eosinophilic infiltration that was associated with increased gene and protein expression of the T helper cell type 2 (Th2) cytokines IL-4, IL-5, and IL-13 (30). This indicated that $\mathrm{CD}^{+} \mathrm{Th} 2$ lymphocytes were important in inducing the lung eosinophilic infiltration. In our study, the eosinophil response of adults to Sephadex beads was markedly increased despite no significant increase in IL-4 release. In contrast, the eosinophil response of pups was lower, even though IL-4 was increased significantly. Thus, the biologic significance of IL-4 in this animal model remains unclear. Among Th2 cytokines, IL-5 played an important role in eosinophil maturation, chemoattraction, and activation (40). For example, Das et al. (14) demonstrated a requirement for IL-5 in the development of lung eosinophilic infiltration after Sephadex bead treatment using an anti-IL-5 MAb. However, we did not measure IL-5 concentration in the BALF from either adults or pups because a commercially available assay was not available.

In the present study, the difference in granuloma size between rat adults and pups was not due to the number of the beads in an area of lung. However, we did not determine whether the difference in vascular bed around the Sephadex beads clogging the small vessels or immune response to polysaccharide was associated with the different responses.

We have shown that Sephadex beads markedly elicited granulomatous lesion with infiltration of eosinophils and neutrophils in the adult lung, whereas pups did not respond as rapidly to the treatment. The different responses in the two groups may be related to the kinetics of cytokine and chemokine production. Therefore, our animal model is for clarifying the mechanism and developmental changes in granuloma formation and accumulation of eosinophils and neutrophils in the lung.

Acknowledgments. We are grateful to Professor Seiji Kojima of the Department of Pediatrics, Nagoya University Graduate School of Medicine (Nagoya, Japan), for his kind suggestion.

\section{REFERENCES}

1. Adams DO 1976 The granulomatous inflammatory response. Am J Pathol 84:164191

2. Boros DL 1978 Granulomatous inflammations. Prog Allergy 24:183-267

3. Kunkel SL, Chensue SW, Strieter RM, Lynch JP, Remick DG 1989 Cellular and molecular aspects of granulomatous inflammation. Am J Respir Cell Mol Biol $1: 439-447$

4. Warren KS 1976 A functional classification of granulomatous inflammation. Annu NY Acad Sci 278:7-18

5. Chensue SW, Otterness IG, Higashi GI, Forsh CS, Kunkel SL 1989 Monokine production by hypersensitivity (Schistosoma mansoni egg) and foreign body (Sephadex bead)-type granuloma macrophages. Evidence for sequential production of IL-1 and tumor necrosis factor. J Immunol 142:1281-1286

6. Chensue SW, Warmington K, Ruth J, Lincoln P, Kuo M-C, Kunkel SL 1994 Cytokine responses during mycobacterial and schistosomal antigen-induced pulmonary granuloma formation. Production of Th1 and Th2 cytokines and relative contribution of tumor necrosis factor. Am J Pathol 145:1105-1113

7. Walls RS, Beeson PB 1972 Mechanism of eosinophilia. IX. Induction of eosinophilia in rats by certain forms of dextran. Proc Soc Exp Biol Med 140:689-693

8. Sorden SD, Lemanske RF, Castleman WL 1990 Pulmonary eosinophilia and granulomatous pulmonary arteritis induced in rats by intravenous Sephadex. Vet Pathol 27:217-222

9. Kubin R, Deschl U, Linssen M, Wilhelms OH 1992 Intratracheal application of Sephadex in rats leads to massive pulmonary eosinophilia without bronchial hyperreactivity to acetylcholine. Int Arch Allergy Immunol 98:266-272

10. Buyssens N, Loenders B, van den Bossche R, Herman A 1995 Sephadex induced granulomatous reaction in rats. Exp Toxicol Pathol 47:381-390

11. Maghni K, Blanchette F, Sirois P 1993 Induction of lung eosinophilia and neutrophilia in guinea pigs following injection of Sephadex beads. Inflammation 17:537550 
12. Matsubara S, Fushimi K, Kikkawa H, Naito K, Ikezawa K 1998 Difference in inhibitory effects of dexamethasone and cyclosporin A on Sephadex bead-induced airway hyperresponsiveness and inflammation in rats. Jpn J Pharmacol 77:89-98

13. Ito A, Miyake M, Morishita M, Ito K, Torii S, Sakamoto T 2003 Dexamethasone reduces lung eosinophilia, and VCAM-1 and ICAM-1 expression induced by Sephadex beads in rats. Eur J Pharmacol 468:59-66

14. Das AM, Williams TJ, Lobb R, Nourshargh S 1995 Lung eosinophilia is dependent on IL-5 and the adhesion molecules CD18 and VLA-4, in a guinea-pig model. Immunology 84:41-46

15. Guo R, Ward PA, Jordan JA, Huber-Lang M, Warner RL, Shi MM 1999 Eotaxin expression in Sephadex-induced lung injury in rats. Am J Pathol 155:2001-2008

16. Marguet C, Jouen-Boedes F, Dean TP, Warner JO 1999 Bronchoalveolar cell profiles in children with asthma, infantile wheeze, chronic cough, or cystic fibrosis. Am J Respir Crit Care Med 159:1533-1540

17. Bourgeois ML, Goncalves M, Clainche LL, Benoist M-R, Fournet J-C, Scheinmann $\mathrm{P}$, de Blic J 2002 Bronchoalveolar cells in children $<3$ years old with severe recurrent wheezing. Chest 122:791-797

18. Just J, Fournier L, Momas I, Zambetti C, Sahraoui F, Grimfeld A 2002 Clinical significance of bronchoalveolar eosinophils in childhood asthma. J Allergy Clin Immunol 110:42-44

19. Najafi N, Demanet C, Dab I, de Waele M, Malfroot A 2003 Differential cytology of bronchoalveolar lavage fluid in asthmatic children. Pediatr Pulmonol 35:302-308

20. Bousquet J, Chanez P, Lacoste JY, Barneon G, Ghavanian N, Enander I, Venge P, Ahlstedt S, Simony-Lafontaine J, Godard P, Francois-Bernard M 1990 Eosinophilic inflammation in asthma. N Engl J Med 323:1033-1039

21. Bousquet J, Jeffery PK, Busse WW, Johnson M, Vignola AM 2000 Asthma from bronchoconstriction to airways inflammation and remodeling. Am J Respir Crit Care Med 161:1720-1745

22. Lemanske RF, Kaliner MA 1982 The experimental production of increased eosinophils in rat late-phase reactions. Immunology 45:561-568

23. Carlos TM, Harlan JM 1994 Leukocyte-endothelial adhesion molecules. Blood 84:2068-2101

24. Malik AB, Lo SK 1996 Vascular endothelial adhesion molecules and tissue inflammation. Pharmacol Rev 48:213-229

25. Pober JS, Bevilacqua MP, Mendrick DL, Lapierre LA, Fiers W, Gimbrone MA 1986 Two distinct monokines, interleukin 1 and tumor necrosis factor, each independently induce biosynthesis and transient expression of the same antigen on the surface of cultured human vascular endothelial cells. J Immunol 136:1680-1687

26. Lo SK, Everitt J, Gu J, Malik AB 1992 Tumor necrosis factor mediates experimental pulmonary edema by ICAM-1 and CD18-dependent mechanisms. J Clin Inves 89:981-988

27. Lukacs NW, Chensue SW, Strieter RM, Warmington K, Kunkel SL 1994 Inflammatory granuloma formation is mediated by TNF- $\alpha$-inducible intracellular adhesion molecule-1. J Immunol 152:5883-5889
28. Renzetti LM, Paciorek PM, Tannu SA, Rinaldi NC, Tocker JE, Wasserman MA, Gater PR 1996 Pharmacological evidence for tumor necrosis factor as a mediator of allergic inflammation in the airways. J Pharmacol Exp Ther 278:847-853

29. Gater PR, Wasserman MA, Paciorek PM, Renzetti LM 1996 Inhibition of Sephadexinduced lung injury in the rat by Ro 45-2081, a tumor necrosis factor receptor fusion protein. Am J Respir Cell Mol Biol 14:454-460

30. Haddad E, Underwood SL, Dabrowski D, Birell MA, McCluskie K, Battram CH, Pecoraro M, Foster ML, Belvisi MG 2002 Critical role for T cells in Sephadexinduced airway inflammation: pharmacological and immunological characterization and molecular biomarker identification. J Immunol 168:3004-3016

31. Gifford GE, Lohmann-Matthes ML 1987 Gamma interferon priming of mouse and human macrophages for induction of tumor necrosis factor production by bacterial lipopolysaccharide. J Natl Cancer Inst 78:121-124

32. Gosset P, Tsicopoulos A, Wallaert B, Joseph M, Capron A, Tonnel A 1992 Tumor necrosis factor alpha and interleukin- 6 production by human mononuclear phagocytes from allergic asthmatics after IgE-dependent stimulation. Am Rev Respir Dis 146:768-774

33. Jose PJ, Adcock IM, Griffiths-Johnson DA, Berkman N, Wells TNC, Williams TJ, Power CA 1994 Eotaxin: cloning of an eosinophil chemoattractant cytokine and increased mRNA expression in allergen-challenged guinea-pig lungs. Biochem Biophys Res Commun 205:788-794

34. Gonzalo JA, Jia GQ, Aguirre V, Friend D, Coyle AJ, Jenkins NA, Lin GS, Katz H, Lichtman A, Copeland N, Kopf M, Gutierrez-Ramos JC 1996 Mouse eotaxin expression parallels eosinophil accumulation during lung allergic inflammation but it is not restricted to a Th2-type response. Immunity 4:1-14

35. MacLean JA, Ownbey R, Luster AD 1996 T cell-dependent regulation of eotaxin in antigen-induced pulmonary eosinophilia. J Exp Med 184:1461-1469

36. Humbles AA, Conroy DM, Marleau S, Rankin SM, Palframan RT, Proudfoot AEI, Wells TNC, Li D, Jeffery PK, Griffiths-Johnson DA, Williams TJ, Jose PJ 1997 Kinetics of eotaxin generation and its relationship to eosinophil accumulation in allergic airways disease: analysis in a guinea pig model in vivo. J Exp Med 186:601-612

37. Harrington PM, Newton DJ, Williams CMM, Hunt JA, Dearman RJ, Kimber I, Coleman JW, Flanagan BF 1999 Eotaxin and eotaxin receptor (CCR3) expression in Sephadex particle-induced rat lung inflammation. Int J Exp Pathol 80:177-185

38. Kameyoshi Y, Dorschner A, Mallet AI, Christophers E, Schroder JM 1992 Cytokine RANTES released by thrombin-stimulated platelets is a potent attractant for human eosinophils. J Exp Med 176:587-592

39. Rot A, Krieger N, Brunner T, Bischoff SC, Schall TJ, Dahinden CA 1992 RANTES and macrophage inflammatory protein I alpha induce the migration and activation of normal human eosinophil granulocytes. J Exp Med 176:1489-1495

40. Barnes PJ, Chung KF, Page CP 1998 Inflammatory mediators of asthma. Pharmaco Rev 50:515-596 